\title{
El discurso de la crítica literaria. Dominio y término
}

Bertha ACEVES

Universidad Nacional Autónoma de México

La tarea tradicional de la crítica literaria desde su inicio, como modelo discursivo, ha sido describir, interpretar y comentar las obras literarias. Según refiere Wal ter Mignolo, el término de crítica "pasó a designar, en la modernidad, una manera de conversar sobre la literatura que en la edad clásica llevaba el nombre de comentario ( $c f$. los "comentaristas" de Garcilaso o de Góngora). Y el comentario, como luego el "ensayo", es un modo de expresión, de conversar sobre la literatura y sobre las obras literarias".' En la actualidad, la crítica literaria se presenta como un tipo de discurso que pretende no únicamente comentar, sino validar los textos literarios como literarios o no literarios.

Esta tarea se explica, según Foucault, porque se ha manifestado, en las formaciones discursivas, una voluntad de decir verdad, la cual ha sido característica persistente y "ha atravesado tantos siglos de nuestra historia". ${ }^{2}$ A partir de los siglos XVI y XVII y como una nueva forma de manifestarse la búsqueda de la verdad, nace una "voluntad de saber" que se propuso:

[... dibujar] planes de objetos posibles, observables, medibles [...]; que imponía al sujeto conocedor [...] una cierta posición, una cierta forma de mirar y una cierta función; [...] que prescribía el nivel técnico del que los conocimientos deberían investirse para ser verificables y útiles. ${ }^{3}$

Estas modalidades del saber se apoyaron en prácticas institucionales como la enseñanza, la edición de libros, las sociedades de intelectuales, la organización de bibliotecas, y tuvieron una distribución también de carácter institucional. Lo cual:

${ }^{1}$ Walter Mignolo, Teoria del texto e interpretación de textos. México, UNAM, 1986, p. 32.

${ }^{2}$ Michel FoucaulT, El orden del discurso. Barcelona. Tusquets, 1973, p. 15.

${ }^{3}$ Ibid., p. 17. 
[... ejerce] sobre los otros discursos [...] una especie de presión y como un poder de coacción. Pienso en cómo la literatura occidental ha debido buscar apoyo desde hace siglos sobre lo natural, lo verosímil, [...] sobre la ciencia —en resumen sobre el discurso verdadero. ${ }^{4}$

Lo dicho por Foucault sobre la literatura se puede aplicar también al discurso de la crítica literaria, la cual -y siguiendo los puntos anteriormente señalados cuando se genera en el discurso una "voluntad de saber" - ha tenido como proyecto el observar, medir y clasificar los objetos que selecciona como literarios; el establecer un determinado espacio social para quien produce el discurso de la crítica literaria; así como el aceptar distintas técnicas de análisis, y diversos tipos de discursos, como el psicológico, el filosófico, el histórico, el lingüístico, etcétera, todo ello con el propósito de presentarse como un discurso científico y validarse como un discurso verdadero.

De esta manera, en nuestro ámbito literario, se ha buscado conceder este estatuto al "comentario" literario: así, José Luis Martínez festeja la llegada de la "Ciencia de la Literatura", para sustentar el decir de la crítica literaria; 5 a su vez, Alfonso Reyes la llama: "la ciencia de la literatura"; 6 por esos años, en España, Dámaso Alonso afirma que "la estilística será la única 'Ciencia de la Literatura' "?

Acorde con esta función asignada a la crítica literaria, y en opinión de Octavio Paz, "en nuestra época la crítica funda la literatura". 8 Por otro lado, Jorge von Ziegler considera que el trabajo del crítico permite "hacer evidente su lugar [el de la obra estudiada] en la historia literaria". ${ }^{9}$ Así, es aceptado el discurso de la crítica, como un medio de inclusión o exclusión de los textos en el estatuto de literarios. Esta función del "comentario", especifica Foucault, es uno de los controles y delimitaciones internas propias del discurso. Aunque no se refiere en particular a la crítica literaria, sino al uso del "comentario" en el discurso, lo afirmado por él es aplicable a la singularidad del "comentario" literario e ilustra muy bien su dominio: "el comentario conjura el

${ }^{4}$ Ibid., p. 18.

${ }^{5}$ Cf. José Luis MARTínez, "Introducción a la estilistica", en Problemas literarios. México, Obregón, 1943, p. 123.

${ }^{6}$ Cf. Alfonso REYES, "El deslinde", en Obras completas, vol. 15. México, FCE, 1963.

${ }^{7}$ Dámaso Alonso, Elmétodo ylos límites de la estilistica. Madrid, Gredos, 1952, p. 400.

${ }^{8}$ Octavio PAZ, Corriente alterna. México, Siglo XXI, 1967, p. 44.

9 Jorge von ZIEGLER, "Para leer la crítica mexicana", en Universidad de México, vol. XLV, núm. 468. México, enero, 1990, p. 9. 
azar del discurso al tenerlo en cuenta: permite decir otra cosa aparte del mismo, pero con la condición de que sea ese mismo texto el que se diga, y en cierta forma, el que se realice". ${ }^{10}$

El comentario busca hacerse transparente para que aparezca "por fin lo que estaba articulado silenciosamente allá lejos"; " se enmascara y habla con la voz del texto literario, encubrimiento que le permite proponerse como una certidumbre; lectura que al "conjurar" cierra la multiplicidad de sentidos contenidos en una obra, pero no para clausurarlos ni para limitarlos a una única interpretación, sino para desatar las voces encerradas en la obra; esto es, "decir por primera vez aquello que sin embargo había sido ya dicho". ${ }^{12}$ Por eso, el comentario, según lo ha explicado Barthes, no "traduce" la obra literaria sino que "engendra" otro sentido: "la crítica desdobla los sentidos, hace flotar un segundo lenguaje por encima del primer lenguaje de la obra, es decir, una coherencia de signos". 13

Por eso, el discurso de la crítica literaria no resuelve ni define ni tiene jamás la última verdad; pero sí es una actividad que formula los principios rectores que se establecen en una comunidad determinada para validar o no los textos literarios. De aquí que necesite de espacios sociales institucionalizados (las editoriales, los periódicos, las universidades, las asociaciones de escritores, los premios literarios, etcétera), desde los cuales se reconozca su decir como un decir autorizado; porque uno de los principios que limitan la distribución del discurso es que "cualquiera no puede hablar de cual quier cosa". ${ }^{14}$ A sí, quien hable tiene que estar calificado para ingresar a la "comunidad interpretativa", según llama Mignolo a la instancia social que tiene la función de interpretar la literatura, en una comunidad determinada y en una época histórica dada. ${ }^{15}$

En la interrelación de los dos lenguajes, en la "frotación" del lenguaje de la crítica con el del texto literario, como diría Barthes, se produce una lectura que "descubre" una particular evaluación de la obra literaria. En el momento de la recepción, cuando su valor, como texto literario, es aceptado o no, éste "debe conformarse a las exigencias (expectativas) de la comunidad en cuestión". ${ }^{16} \mathrm{Si}$ la obra literaria, en el momento de su

${ }^{10}$ M. FoucaulT, op. cit., p. 25.

11 Ibid., p. 23.

12 Ibid.

13 Roland BARTHES, Critica y verdad. México, Siglo XXI, 1972, p. 68.

${ }^{14}$ M. FoUCAULT, op. cit., p. 12.

${ }^{15} \mathrm{C} f$. W. MigNoLO, op. cit. 
lectura, no cumple con la norma vigente, entonces se le clasifica acorde con los valores en observancia, los cuales pueden coincidir o no con los valores del momento de la producción del texto artístico.

Por ello, no es sorprendente encontrar opiniones, en la historia de la literatura, que estén en desacuerdo con los valores del momento de la producción de una obra literaria. Si se está conforme con la propuesta de que la literatura es un valor histórico y cultural, porque "lo literario no es una cualidad diferencial, intrínseca, de los textos, sino una cualidad asignada en los marcos de una cultura dada", ${ }^{17}$ entonces la valoración de los textos cambia acorde con el momento de la recepción; por ello, un texto evaluado como excelente cuando fue escrito, al paso del tiempo puede ser considerado como de nulo o poco valor.

Un buen ejemplo lo encontramos en la historia de la literatura mexicana, donde se recoge la opinión que tenía la generación de los escritores mexicanos del romanticismo sobre la literatura novohispana. Ellos partían de un principio común en ese momento: afirmaban que la literatura no nace en los pueblos esclavizados, porque "la opresión pesa de manera perniciosa sobre la inteligencia", según dijera el Zarco. Sobre esta forma de considerar la literatura, explica Luis Mario Schneider, "los románticos eran intransigentes frente a este asunto: despreciaban la opresión dictatorial española [...] no podía haber literatura durante la conquista pues ella es reflejo y resultado de un medio libertario y pacífico". ${ }^{18}$

Razón por la cual no concedieron ningún mérito literario a los escritores que vivieron durante la época colonial; ni siquiera a sor Juana Inés de la Cruz (célebre escritora para la crítica actual). Así, con sorpresa se escucha la opinión del Zarco sobre esta poetisa, según la recoge y narra Schneider:

[...] está llena de defectos y mal gusto, pero tenía imaginación, valentía y sensibilidad; era, en definitiva, "una verdadera curiosidad colonial". Para Altamirano no hay que recomendar la lectura de la Décima Musa, a quien hay que dejar "quietecita en el fondo de su sepulcro y entre el pergamino de sus libros, sin estudiarla para admirar de paso la rareza de sus talentos y para lamentar que hubiera nacido

${ }^{16}$ Ibid., p. 33.

${ }^{17}$ César GonzÁLEZ, Función de la teoría en los estudios literarios. México, UNAM, 1982 , p. 156.

${ }^{18}$ Luis Mario SCHNEIDER, Ruptura y continuidad. La literatura mexicana en polémica. México, FCE, 1975, p. 83. 
en tiempos del culteranismo y de la Inquisición y de la teología escolástica". Cuéllar la define como testimonio de la implantación de la literatura española "con todos sus vicios, hinchazón y gongorismo". ${ }^{19}$

¿Cuándo fue sor Juana reivindicada y reconocida como una escritora de mérito? Octavio Paz describe el proceso de su revitalización, cuando su voz deja de ser un "pergamino" y se transforma - gracias a los aires nuevos que soplaron después de la Revolución mexicana- en letra viva; así, relata "el acontecimiento de su retorno" a la literatura nacional:

El que encendió la chispa del reconocimiento, en México, fue un poeta: Amado Nervo. Su libro (Juana de Asbaje, 1910) [...] Más tarde, entre 1910 y 1930, abundaron los estudios de erudición: había que desenterrar y fijar los textos. A los trabajos de Manuel Toussaint sucedieron los del infatigable Ermilo Abreu Gómez [...] Los poetas de Contemporáneos leyeron con simpatía y provecho a sor Juana, sobre todo Jorge Cuesta y Xavier Villaurrutia, que editó los Sonetos y las Endechas. ${ }^{20}$

Con el anterior ejemplo se hace evidente que "los principios vigentes de la comunidad literaria varían, aunque la comunidad se reconozca el sustantivo (literatura, poesía) que la identifica". ${ }^{21}$ Las diversas modalidades de evaluación que se generan durante el proceso de la producción y de las distintas recepciones que un texto tiene, muestran "que la comunidad opera en una multiplicidad de paradigmas que obligan a aceptar que literatura sea un concepto abierto". ${ }^{22}$ Por ello, no se puede establecer una única interpretación acerca de un texto literario, a pesar de que el decir de la crítica literaria se sustente en la "voluntad de verdad" que ha definido a esta práctica discursiva.

Los cambios se generan a partir de las determinaciones históricas que prevalecen en una "comunidad" particular y en un tiempo específico; consecuentemente, el comentario tiene el término que le confieren las múltiples contradicciones históricas que determinan su situación. Sobre este problema que enfrenta la lectura de un texto literario, la que no es sólo una relación entre un lector enfrascado en la exégesis de una obra

19 Apud L. M. SCHNEIDER, op. cit., p. 84.

${ }^{20}$ Octavio PAZ, Sor Juana Inés de la Cruz o Las trampas de la fe. México, FCE, 1982, p. 11.

21 W. MignOLO, op. cit., p. 33.

22 Idem. 
literaria, dejo hablar a César González, quien introduce el concepto freudiano de la sobredeterminación para explicar las varias causas que influyen en el análisis concreto de una situación. En este análisis, dice,

[...] se sintetizan múltiples determinaciones o lo que es lo mismo, el análisis de una situación sobredeterminada. La sobredeterminación se encuentra presente en cualquier momento histórico, en cualquier proceso, ya que se trata del modo de ser de la contradicción. Puede afirmarse que si cada coyuntura o cada acontecimiento constituye un caso único e irrepetible, ello se debe precisamente a la sobredeterminación, concepto que se opone a la idea de una determinación unidimensional. ${ }^{23}$

Los criterios generales que guían a una "comunidad literaria" están sujetos a las contradicciones y complejidades de su momento; el decir de la crítica literaria, como parte de esta entidad, tampoco puede evitar los marcos históricos y la multiplicidad de contradicciones que lo determinan, lo cual no invalida su palabra; únicamente la limita a un decir ceñido por el espacio y el tiempo desde donde habla.

${ }^{23}$ César GonZÁLEZ, "El momento de la lectura", en Cuadernos de Filosofia y Letras, núm. 3. México, UNAM, 1985, p. 79. 